\title{
Atividade Antimicrobiana do Extrato Bruto da Moringa oleifera Lam em Função do Binômio Tempo/Temperatura.
}

João Paulo Gomes de Sousa (I), Carolini Esmeriz da Rosa (I), Daiane Evelin dos Santos Assunção (I), Ed Carlo Rosa Paiva (I), Jupyracyara Jandyra de Carvalho Barros (I)

(I) UFG/RG - UNIVERSIDADE FEDERAL DE GOIÁS, REGIONAL CATALÃO (Av.: Dr. Lamartine P. Avelar, 1120, Bairro: Setor Universitário; Catalão - GO)

\section{Resumo}

Dentre os diversas espécies vegetais com propriedade antimicrobiana destaca-se a Moringa oleifera Lam., que se caracteriza por apresentar valor econômico e medicinal. Nesse sentido, esse estudo teve como objetivo avaliar a estabilidade da atividade antimicrobiana do extrato bruto aquoso de sementes de Moringa oleifera Lam. em relação ao tempo/temperatura. Para o preparo do extrato, 30 gramas das sementes da planta, previamente trituradas, foram homogeneizadas com agitação magnética à temperatura ambiente durante 30 minutos com $150 \mathrm{~mL}$ de água destilada (1:5).

Alíquotas de $50 \mu \mathrm{L}(0,05 \%), 100 \mu \mathrm{L}(0,10 \%), 150 \mu \mathrm{L}(0,01 \%)$ e $200 \mu \mathrm{L}$ $(0,20 \%)$ dos extratos mantidos em temperatura ambiente, $8^{\circ} \mathrm{C}, 37^{\circ} \mathrm{C}$ e $42^{\circ}$ $\mathrm{C}$, durante o período de $0,3,7$ e 10 dias foram aplicadas em discos de papel estéreis de $6 \mathrm{~mm}$ de diâmetro. Esses foram depositados em placas de Petri contendo Agar Müeller Hinton, previamente semeadas com culturas de Escherichia coli ATCC 25922, Staphylocococcus aureus ATCC 25923 e Pseudomonas aeruginosa ATCC 27853, padronizadas em escala 0,5 McFarland. A medição do diâmetro do halo foi realizada após 18 a 24 horas de incubação a $37^{\circ} \mathrm{C}$. A sensibilidade das culturas testes ao extrato foi considerada para os halos de inibição maiores que $13 \mathrm{~mm}$. A única bactéria susceptível foi Staphylococcus aureus ATCC 25923, sendo os maiores halos de inibição encontrados no tempo zero $(17 \mathrm{~mm} ; 22 \mathrm{~mm})$, para 
todas as concentrações/temperatura. Os extratos mantidos a $8{ }^{\circ} \mathrm{C}$ tiveram seu efeito inibidor mantido por mais tempo. A instabilidade do extrato é verificada a partir 72 horas de incubação, tal resultado pode ser justificado pelo acúmulo de resíduos orgânicos advindos das reações enzimáticas favorecidas à temperatura ambiente, $37^{\circ} \mathrm{C} \mathrm{e} 42^{\circ} \mathrm{C}$.Os resultados deste estudo indicam o potencial de aplicação do extrato da semente de Moringa oleifera Lam. como uma alternativa interessante na conservação de gêneros alimentícios, excessivamente manipulados e comercializados em temperatura de refrigeração.

Palavras-Chave: Estabilidade térmica, Extrato vegetal, Período de estocagem

Agência de Fomento: 